\title{
Vapor-Phase Infrared and Raman Spectra and Ab-Initio Calculations of the Axial and Equatorial forms of Cyclohexane- $\mathrm{d}_{1}$ and $\mathrm{d}_{11}$
}

\author{
Hye Jin Chun, Esther J. Ocola, and Jaan Laane* \\ Department of Chemistry, Texas A\&M University, College Station, TX 77843-3255
}

\begin{abstract}
The vapor-phase infrared and Raman spectra of cyclohexane- $\mathrm{d}_{11}$ in the C-H stretching region show two bands at 2,891 and 2,921 $\mathrm{cm}^{-1}$ corresponding to the axial and equatorial C-H stretching modes respectively. Similarly, cyclohexane- $\mathrm{d}_{1}$ has two C-D stretching modes at 2,145 and 2,164 $\mathrm{cm}^{-1}$ [1] corresponding to the two forms. Force constants were calculated for these vibrations and these confirm the theoretical calculations, which show the equatorial bonds to be shorter and stronger. The force constant for the equatorial C-H stretching is $2 \%$ higher than for the axial.
\end{abstract}

* Corresponding author email: LAANE@MAIL.CHEM.TAMU.EDU

Keywords: cyclohexane; conformations; ab initio; DFT; C-H stretching; vibrations

(C) 2016. This manuscript version is made available under the Elsevier user license http://www.elsevier.com/open-access/userlicense/1.0/ 


\section{INTRODUCTION}

The cyclohexane molecule in its lowest energy form exists in the chair conformation with $\mathrm{D}_{3 \mathrm{~d}}$ symmetry. Its $\mathrm{d}_{1}$ singly deuterated isotopomer has the unusual property that the C-D bond can either be axial or equatorial. Similarly, cyclohexane- $\mathrm{d}_{11}$, which has only one ${ }^{1} \mathrm{H}$ atom, has two distinct conformers where the C-H bond can be axial or equatorial. In 1984 Matrai and Gal [1] observed the C-D stretching bands for the $\mathrm{d}_{1}$ vapor at $2,145 \mathrm{~cm}^{-1}$ (assigned to the axial) and $2,164 \mathrm{~cm}^{-1}$ (equatorial). The corresponding Raman bands for the liquid were at 2,144 and 2,162 $\mathrm{cm}^{-1}$. In 1987 Gough and Murphy [2] reported the C-H stretching frequencies for the $\mathrm{d}_{11}$ isotopomer to be at $2,891 \mathrm{~cm}^{-1}$ for the axial form and $2,923 \mathrm{~cm}^{-1}$ for the equatorial. Numerous theoretical studies have been carried out on the conformations of cyclohexane [3-6]. These agree that the equatorial bond is shorter than the axial bond. In the present study we have recorded the vapor-phase infrared and Raman spectra of cyclohexane- $\mathrm{d}_{11}$ and also carried out theoretical calculations. From the spectra we calculated the force constants for the equatorial and axial C-H bonds and we correlated these to the calculated $\mathrm{C}-\mathrm{H}$ bond distances.

\section{EXPERIMENTAL}

The sample of cyclohexane- $\mathrm{d}_{11}(98$ atom \% D) was purchased from CDN isotopes and was purified by trap-to-trap distillation. Infrared spectra were recorded using a Bruker Vertex 70 instrument, which was purged by a stream of dry nitrogen gas. 
Raman spectra were recorded with a Jobin Yvon U-1000 spectrometer equipped with a charge-coupled device (CCD) detector with a resolution of $0.7 \mathrm{~cm}^{-1}$. A Coherent Verdi V10 $\mathrm{Nd}$ :YAG laser operating at $532 \mathrm{~nm}$ and with $4 \mathrm{~W}$ power at the sample was the excitation source. The vapor Raman spectra was recorded at $98^{\circ} \mathrm{C}$. A special heatable Raman cell, which has been previously described [7,8], was utilized.

\section{COMPUTATIONS}

Structure calculations. The cc-pVTZ (triple- $\zeta$ ) basis set was used with the second-order Møller-Plesset (MP2) ab initio method to calculate the energies and to compute the geometries of the conformations of cyclohexane. The Gaussian 09 program [9] was used for the computations, and the Semichem AMPAC/AGUI program [10] was used to visualize the structures.

Frequency calculations. The vibrational frequencies of the chair conformation of cyclohexane- $d_{1}$ and $-d_{11}$ along with their Raman intensities were calculated by using the Gaussian 09 program. The density functional theory (DFT) B3LYP method [11,12] was used with the cc-pVTZ basis set. The scaling factor of 0.961 was used for the vibrations of interest, based on previous work [13-18], which also has shown us that B3LYP/cc-pVTZ calculations do a better job than MP2/cc-pVTZ for reproducing vibrational frequencies.

\section{RESULTS AND DISCUSSION}

Figure 1 shows the vapor-phase infrared and Raman spectra of cyclohexane-d $\mathrm{d}_{11}$ in the $\mathrm{C}-\mathrm{H}$ stretching region. The two bands at 2,921 and $2,891 \mathrm{~cm}^{-1}$ clearly arise from the two conformational forms. Treating these vibrations with the harmonic oscillator model for a diatomic molecule allows us to calculate the force constants to be $4.646 \mathrm{mdynes} / \AA$ for the 
equatorial C-H and 4.551 mdynes/Å for the axial C-H. Similarly, we can use the literature values [1] for the C-D stretching vibrations of cyclohexane- $\mathrm{d}_{1}$ and we calculate force constants of 4.736 mdynes/A for the equatorial form and 4.653 mdynes/A for the axial form. These results are shown in Table 1. Ideally the force constants for the two isotopomers should be the same for the corresponding vibrations of the $d_{1}$ and $d_{11}$ molecules, but the calculations were carried out assuming the harmonic oscillator model for diatomic molecules. Hence, the anharmonicity has the effect of apparently increasing the force constant for the C-D stretching since the quantum states are deeper within the potential well. In addition, the C-D stretch being of lower frequency has increased coupling with the other vibrational modes. In any case, for the $\mathrm{C}-\mathrm{H}$ stretch the force constant for the equatorial vibration is $2.1 \%$ higher than for the axial. For the C-D stretching it is $1.8 \%$ higher.

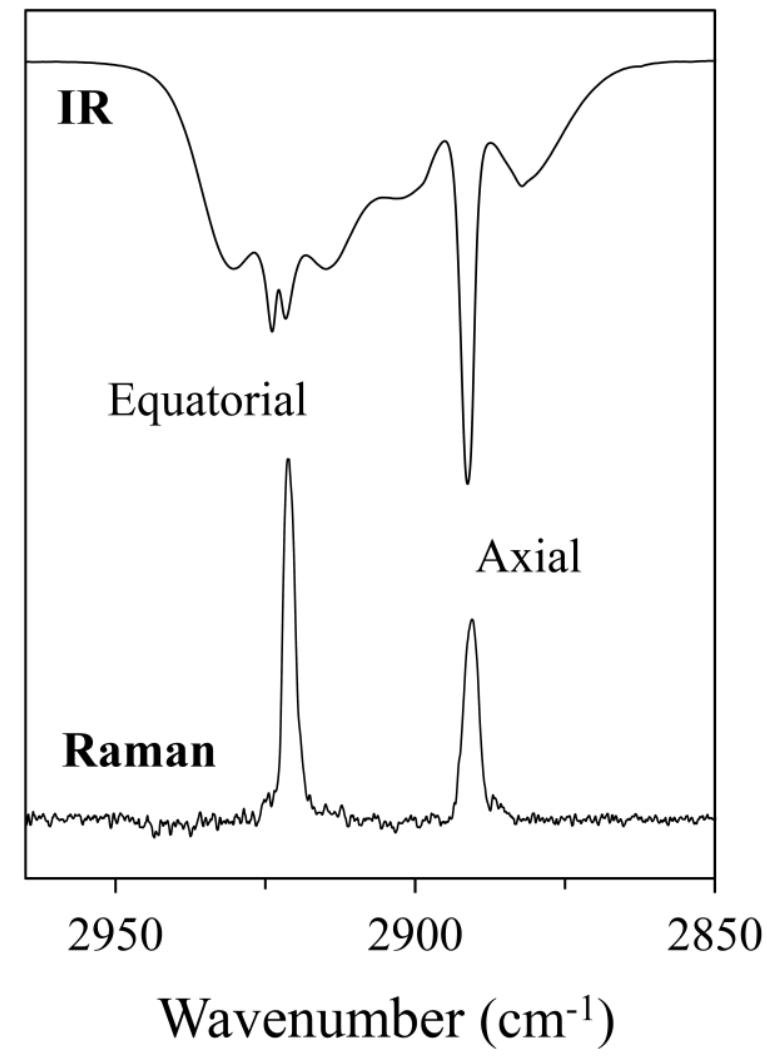

Figure 1. Vapor-phase infrared and Raman spectra of cyclohexane- $\mathrm{d}_{11}$ in the C-H stretching region. 
The calculated (DFT) B3LYP/cc-pVTZ frequency difference between the C-H axial and equatorial modes of $29 \mathrm{~cm}^{-1}(2,921-2,892)$ agrees almost perfectly with the observed difference of $30 \mathrm{~cm}^{-1}$. For the C-D stretch of the $\mathrm{d}_{1}$ molecule the reported experimental difference is $19 \mathrm{~cm}^{-1}[1]$ compared to our calculated difference of $23 \mathrm{~cm}^{-1}$.

Table 1. $\mathrm{C}-\mathrm{H}$ and $\mathrm{C}-\mathrm{D}$ stretching frequencies, force constants and bond distance for cyclohexane- $\mathrm{d}_{11}$ and $\mathrm{d}_{1}$.

\begin{tabular}{|c|c|c|}
\hline C-H stretching $\left(d_{11}\right)$ & Axial & Equatorial \\
\hline Frequency $\left(\mathrm{cm}^{-1}\right)$ & 2891 & 2921 \\
\hline Force constant (mdyne/Å) & 4.551 & 4.646 \\
\hline Bond distance $(\AA)$ & 1.094 & 1.091 \\
\hline \multicolumn{3}{|l|}{ C-D stretching $\left(d_{1}\right)$} \\
\hline Frequency $\left(\mathrm{cm}^{-1}\right)^{\mathrm{a}}$ & 2145 & 2164 \\
\hline Force constant (mdyne/Å) & 4.653 & 4.736 \\
\hline Bond distance $(\AA)$ & 1.094 & 1.091 \\
\hline
\end{tabular}

${ }^{\mathrm{a}}$ Ref. [1]

Figure 2 shows the calculated $\mathrm{C}-\mathrm{H}$ bond distance of the cyclohexane molecule in its chair, boat and twist-boat conformations. As can be seen, for the chair conformation, the equatorial $\mathrm{C}-\mathrm{H}$ bond distances are shorter $(1.091 \AA)$ than those for the axial C-H bonds (1.094 $\AA$ ). This is totally consistent with the calculated force constants which show the equatorial C-H bonds to be stronger. Figure 2 shows that the calculated ab initio MP2/cc-pVTZ C-H bond distances for the boat and twist-boat conformations also depend slightly on the position of the C$\mathrm{H}$ bond, but not nearly as much as for the chair confomation. In our previous work on cyclopentane [19] we found that for the bent conformations the calculated ab initio CCSD/ccpVTZ equatorial C-H bond length of $1.090 \AA$ is shorter than the axial bond length of $1.094 \AA$. 


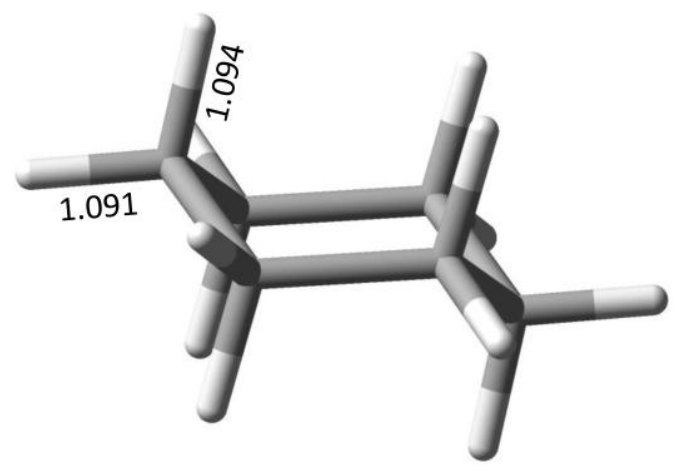

Chair

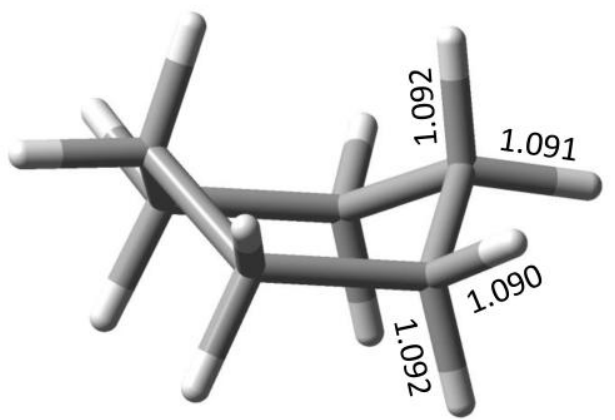

Boat

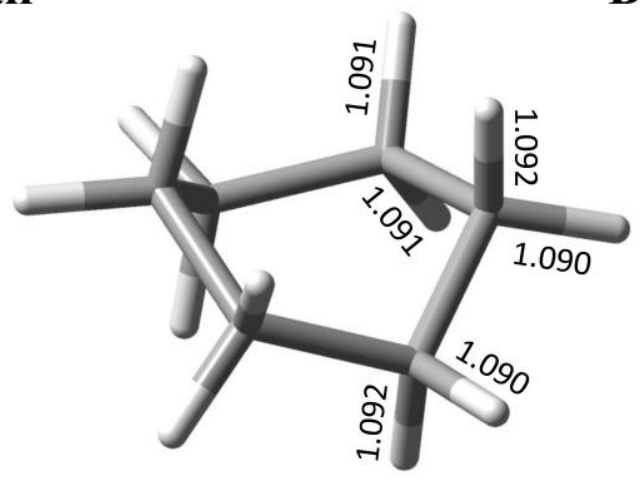

Twist-boat

Figure 2. A $b$ initio MP2/cc-pVTZ calculated C-H bond distances of cyclohexane in its chair, boat, and twist-boat conformations.

\section{CONCLUSIONS}

It is interesting to note how isotopically substituted molecules can be invaluable for experimentally verifying the results of theoretical computations. Namely, they help to show that the equatorial C-H bonds of cyclohexane are stronger than the axial ones.

\section{ACKNOWLEDGEMENTS}

The authors wish to thank the Robert A. Welch Foundation (Grant A-0396) for financial support. Computations were carried out on the Texas A\&M University Department of Chemistry 
Medusa computer system funded by the National Science Foundation, Grant No. CHE-0541587.

The Laboratory for Molecular Simulation provided the Semichem AMPAC/AGUI software.

\section{REFERENCES}

[1] E. Mátrai, M. Gal, J. Mol. Struct. 115 (1984) 431-434.

[2] K.M. Gough, W.F. Murphy, J. Chem. Phys. 87 (1987) 1509-1519.

[3] G. Brügger, H.-M. Frey, P. Steinegger, F. Balmer, S. Leutwyler, J. Phys. Chem. A 115 (2011) 9567-9578.

[4] J.R. Durig, C. Zheng, A.M. El Defrawy, R.M. Ward, T.K. Gounev, K. Ravindranath, R. Rao, J. Raman Spectrosc. 40 (2009) 197-204.

[5] K. Kakhiani, W. Hu, D. Birney, W.L. Hase, J. Phys. Chem. A 113 (2009) 4570-4580

[6] C. Riehn, V.V. Matylitsky, W. Jarzęba, B. Brutschy, P. Tarakeshwar, K.S. Kim, J. Am. Chem. Soc. 125 (2003) 16455-16462.

[7] K. Haller, W.-Y. Chiang, A. del Rosario, J. Laane, J. Mol. Struct. 379 (1996) 19-23.

[8] J. Laane, K. Haller, S. Sakurai, K. Morris, D. Autrey, Z. Arp, W.-Y. Chiang, A. Combs, J. Mol. Struct. 650 (2003) 57-68.

[9] M.J. Frisch, G.W. Trucks, H.B. Schlegel, G.E. Scuseria, M.A. Robb, J.R. Cheeseman, G. Scalmani, V. Barone, B. Mennucci, G.A. Petersson, H. Nakatsuji, M. Caricato, X. Li, H.P. Hratchian, A.F. Izmaylov, J. Bloino, G. Zheng, J.L. Sonnenberg, M. Hada, M. Ehara, K. Toyota, R. Fukuda, J. Hasegawa, M. Ishida, T. Nakajima, Y. Honda, O. Kitao, H. Nakai, T. Vreven, J.A. Montgomery, Jr., J.E. Peralta, F. Ogliaro, M. Bearpark, J.J. Heyd, E. Brothers, K. N. Kudin, V.N. Staroverov, R. Kobayashi, J. Normand, K. Raghavachari, A. Rendell, J.C. Burant, S.S. Iyengar, J. Tomasi, M. Cossi, N. Rega, J.M. Millam, M. Klene, J.E. Knox, J.B. 
Cross, V. Bakken, C. Adamo, J. Jaramillo, R. Gomperts, R.E. Stratmann, O. Yazyev, A.J. Austin, R. Cammi, C. Pomelli, J.W. Ochterski, R.L. Martin, K. Morokuma, V.G. Zakrzewski, G.A. Voth, P. Salvador, J.J. Dannenberg, S. Dapprich, A.D. Daniels, Ö. Farkas, J.B. Foresman, J.V. Ortiz, J. Cioslowski, and D.J. Fox, Gaussian 09, Revision A.02, Gaussian, Inc., Wallingford CT, 2009.

[10] AGUI program from Semichem, Inc.: Shawnee, KS 66216: www.semichem.com.

[11] A.D. Becke, J. Chem.Phys. 98 (1993) 5648-5652.

[12] C. Lee, W. Yang, R.G. Parr, Phys. Rev. B 37 (1988) 785-789.

[13] E.J. Ocola, J. Laane, J. Phys. Chem. A 120 (2016) 74-80.

[14] H.-L. Sheu, P. Boopalachandran, S. Kim, J. Laane, Chem. Phys. 456 (2015) 28-33.

[15] H.J. Chun, N. Meinander, J.R. Villareal, J. Laane, J. Phys. Chem. A 119 (2015) 410-417.

[16] H.-L. Sheu, N. Meinander, J. Laane, J. Phys. Chem. A 119 (2015) 1478-1485.

[17] E.J. Ocola, H.-W. Shin, J. Laane, Spectrochim. Acta, Part A 136 (2015) 58-63.

[18] A.A. Al-Saadi, E.J. Ocola, J. Laane, J. Phys. Chem. A 114 (2010) 7453-7456.

[19] E.J. Ocola, L. Bauman, J. Laane, J. Phys. Chem. A 115 (2011) 6531-6542. 
Graphical Abstract

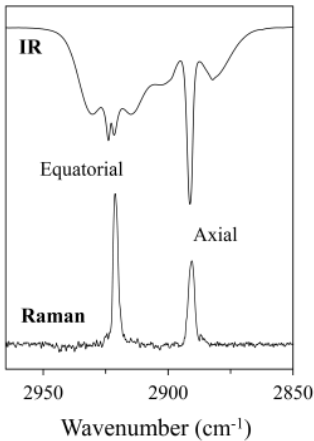

